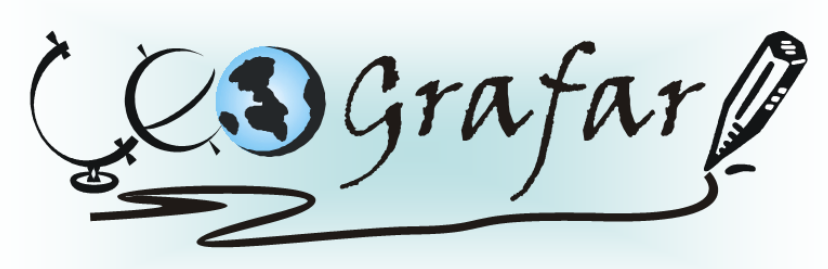

Revista Eletrônica do Programa de Pós-Graduação em Geografia - UFPR

\title{
AGRICULTURA SUSTENTÁVEL: UMA ALTERNATIVA AO MODELO CONVENCIONAL
}

\author{
RENATO GUEDES VIEITES ${ }^{1}$
}

\begin{abstract}
Resumo: Este estudo procura demonstrar a questão da agricultura sustentável como uma alternativa ao modelo agrícola convencional baseado na Revolução Verde e, também, como a agricultura alternativa pode proporcionar uma solução para um dos impasses do futuro - a segurança alimentar. Palavras Chaves: Agricultura Convencional, Revolução Verde, Agricultura Alternativa, Segurança Alimentar
\end{abstract}

\section{SUSTAINABLE AGRICULTURE: AN ALTERNATIVE TO THE CONVENTIONAL AGRICULTURAL MODEL}

Abstract: The aim of this study is to demonstrate the matter of sustainable agriculture as an alternative to the conventional agricultural model, based on the Green Revolution. As well as, the way the alternative agriculture may provide a solution to a future challenge - the nourishment security.

Keywords: Conventional Agriculture, Green Revolution, Alternative Agriculture, Alimentary Security.

\section{INTRODUÇÃO}

Este artigo busca de forma não definitiva e conclusiva realizar um breve resgate histórico acerca da origem e evolução da Agricultura Sustentável, destacando contribuições de alguns autores e demonstrando a importância desta temática para a Geografia. Para tanto, foi realizado um levantamento sistemático de estudos (artigos, monografias de graduação e dissertações de mestrado), bem como de consultas on-line a respeito da sustentabilidade na agricultura.

O presente trabalho foi idealizado e tomou forma como a principal avaliação da disciplina Geografia Agrária do Brasil, feita pelo autor, no curso de graduação em Geografia, na Universidade do Estado do Rio de Janeiro (Uerj) e, como tal, não foi objeto de bolsa e/ou auxílio financeiro de qualquer órgão de fomento. Vale destacar que o presente artigo fez parte do XVIII Encontro Nacional de Geografia Agrária, realizado na Uerj, Rio de Janeiro, no ano de 2006.

\footnotetext{
${ }^{1}$ renatoguedesvieites@hotmail.com
} 
Durante muito tempo, a atividade agrícola esteve relacionada à devastação dos recursos naturais. Com o advento da modernização da agricultura operada no século XX, sob o nome de Revolução Verde, por causa dos métodos adotados, houve uma intensificação da destruição da natureza pelos processos agrícolas agropecuários. Estes processos inegavelmente maximizaram a produção agropecuária, todavia representaram um agravamento dos problemas ambientais, bem como os sócio-econômicos, especialmente nos países emergentes.

As discussões sobre os desdobramentos da Revolução Verde e, principalmente, dos seus impactos ambientais, ganharam força nos anos 1980 do século passado, quando os chamados países desenvolvidos passaram a se dar conta dos problemas ambientais resultantes daquele modelo de agricultura.

Como uma alternativa ao modelo predatório imposto pela agricultura convencional, ergue-se o paradigma da sustentabilidade agrícola, que propõe um desenvolvimento fundamentado na conservação dos recursos naturais $e$ assegurando também às gerações futuras a utilização desses recursos. Desta forma, a agricultura sustentável pode significar ainda um caminho para garantir a segurança alimentar de uma parcela considerável da sociedade, hoje e no futuro.

A primeira parte do estudo refere-se às considerações sobre a revolução verde e a biotecnologia, de forma a demonstrar como estas influenciaram não só a produtividade das lavouras, mas também, todo o processo produtivo. Nessa parte, serão abordados as primeira e segunda revoluções agrícolas.

$\mathrm{Na}$ segunda parte, será estudada a agricultura alternativa ao modelo convencional, onde será feita uma abordagem histórica desde os primeiros processos agrícolas alternativos, tais como: sustentável, biodinâmica, biológica, orgânica, natural, ecológica, ou ainda do termo agroecologia. Apesar de serem com significados distintos, apresentam alguns pontos em comum, como a posição crítica aos insumos mecanizados industrializados, tão marcantes na agricultura convencional.

A terceira parte trata do exemplo de aplicação prática da agricultura sustentável em Cantagalo, área rural do município de Rio das Ostras, estado do Rio de Janeiro. Lá, a parceria entre o governo municipal, a Secretaria de Meio Ambiente, Agricultura e Pesca, a Empresa Brasileira de Pesquisa Agropecuária (Embrapa) e os produtores 
familiares, está realizando uma produção de feijão sem a utilização de defensivos agrícolas.

A terceira e última parte mencionará a segurança alimentar e o papel que a agricultura sustentável desempenha nesse contexto, pois a articulação entre o crescimento econômico e a segurança alimentar configura-se como um fator de vital importância para a sustentação do nível de desenvolvimento atual e, mais do que isto, para a superação do subdesenvolvimento visto que não é possível dissociar a garantia, a todas as pessoas, especialmente as mais pobres, de acesso a alimentos, e a conservação e proteção da base de recursos para a produção de alimentos a longo prazo.

\section{CONSIDERAÇÕES SOBRE A REVOLUÇÃO VERDE E A BIOTECNOLOGIA}

A intensificação dos sistemas rotacionais com plantas forrageiras e leguminosas fixadoras de nitrogênio atmosférico no solo, melhorando a sua fertilidade, originou, sustenta Veiga (1991), a chamada Primeira Revolução Agrícola, com a fusão das atividades agrícola e pecuária, significando um enorme salto para a produção da agricultura e minimizando a escassez de alimentos.

A adubação química que começou a ser adotada graças às descobertas do químico alemão Justus von Liebig, em meados do século XIX, substituiu a fertilização baseada nas rotações de culturas e pelo esterco animal, tornando 0 processo produtivo mais simples e aumentando a produtividade das lavouras. Para Ehlers (1994a), no início do século XX, ocorreu a Segunda Revolução Agrícola, com o setor industrial avançando na mecanização e no desenvolvimento genético de novas variedades vegetais.

A Revolução Verde teve o seu início na década de 1960 e se configurou como um processo de incorporação de tecnologias e mecanização no campo, bem como pela necessidade da utilização de insumos e de agrotóxicos com vistas a maximizar a produtividade agrícola.

De acordo com Estefanell, 1997 apud Lima (2000, p.214): 


\begin{abstract}
A Revolução Verde impôs no campo a mecanização, os insumos industriais, o uso intensivo da terra e a alteração das relações de trabalho. Este padrão produtivo aumenta vertiginosamente a produção agrícola, mas não resolve o problema da fome. Isto porque esse modelo beneficiou sobretudo nos países em desenvolvimento, os grandes e médios produtores, contribuindo ainda mais para a concentração da renda e conseqüentemente para o aumento da pobreza(...).
\end{abstract}

Quando se comenta sobre a Revolução Verde, deve ser citada, atualmente, a questão dos alimentos transgênicos, em que a empresa multinacional Monsanto surge como uma das principais referências nesta "segunda" Revolução Verde. Tratase de um processo que, segundo muitos autores e, em especial Costa Neto (1999), é mais destruidor do meio ambiente que a revolução verde original, além de trazer consigo muitos complicadores, como o caso das patentes.

Durante a década de 1980, começaram a ser discutidos e analisados os problemas ambientais, sociais e econômicos gerados pela Revolução Verde. De acordo com Lima (2000), esta, que serve de base para a agricultura convencional, faz a atividade agrícola ser, em muitos países, a maior consumidora de água, bem como, a maior destruidora da fauna e da flora.

Segundo Ehlers (1995), a agricultura convencional provoca alterações no equilíbrio físico, químico e biológico do solo, destruição de florestas e da biodiversidade genética, aumento da suscetibilidade das lavouras ao ataque de pragas e doenças contaminação dos recursos naturais e dos alimentos.

Os danos ambientais mencionados são motivo de preocupação, visto que comprometem a fertilidade dos solos, criando assim, a necessidade do consumo de fertilizantes e adubos químicos, o que gera, um ciclo vicioso de uma utilização cada vez maior de insumos perigosos ao meio ambiente, que podem acarretar riscos para a saúde da população. Para tentar responder a este problema, Ehlers (1994a, p.90) sustenta que "em meados dos anos 80 , a crescente preocupação com o ambiente e com qualidade de vida no Planeta levou ao surgimento de um novo paradigma das sociedades modernas: a sustentabilidade".

O relatório Brundtland, elaborado em 1987, pela Comissão Mundial sobre Meio Ambiente e Desenvolvimento - CMMAD, postula que o desenvolvimento sustentável fundamenta-se em aumentar a capacidade de produção, conservando os parâmetros de consumo, porém observando as potencialidades ecológicas, com 
vistas a atender às demandas básicas da humanidade, bem como suas metas de uma vida melhor, hoje e para as gerações futuras.

\section{AGRICULTURA ALTERNATIVA}

Assim como a idéia de desenvolvimento sustentável (embora saibamos ser este um conceito polêmico e sujeito a críticas), a qualificação da agricultura como sustentável também atrai a atenção tanto de agricultores e técnicos, como da população em geral. Para Ehlers (1994b), esse elevado interesse denota insatisfação com a atual situação da agricultura, bem como a procura por um novo padrão de produção.

O uso da expressão "agricultura sustentável" se torna cada vez mais freqüente, e, na opinião do autor supracitado Op. Cit.(1994b), há a tendência de substituir o adjetivo "alternativo", que caracterizou durante a década de $1970^{2}$ diferentes linhas tecnológicas que se opunham à agricultura convencional, pelo adjetivo "sustentável". Essa é, porém, uma sinonimização equivocada e não apenas entre esses dois termos.

É comum a adoção do termo "agricultura", qualificado como: alternativa, sustentável, biodinâmica, biológica, orgânica, natural, ecológica, ou ainda do termo agroecologia. De acordo com Almeida (1989) e Costa (1993), são termos com significados distintos, apesar de terem alguns pontos em comum, como a posição crítica à agricultura convencional (modelo químico-mecanizado) e a rejeição a insumos industrializados.

Seguindo a linha de raciocínio dos autores anteriormente mencionados, as modalidades de agricultura biodinâmica, orgânica, biológica ou natural, com algumas de suas variantes, consistem em conjuntos de técnicas distintas, de acordo com a representação que cada um de seus idealizadores tem de agricultura, da relação desta com o meio ambiente e com a produção de alimentos.

Conforme sustentam Almeida (1989) e Ehlers (1994b), a agricultura biodinâmica, desenvolvida inicialmente na Suíça por Rudolf Steiner, a partir de 1924,

2 De acordo com Costa (1984), apesar de ter ficado mais popular durante os anos 1970, as "escolas" alternativas surgem juntamente com a difusão do modelo químico-mecânico de agricultura no final do século passado. 
vê a propriedade agrícola como um organismo, considerando fundamental a interação entre a produção animal e a produção vegetal, visando reativar as forças vitais da natureza.

Já a agricultura orgânica considera fundamental a fertilidade do solo, que é mantida em função da aplicação de compostos orgânicos obtidos a partir de resíduos da propriedade agrícola, principalmente resíduos de origem animal (esterco). Op. Cit. (1989); (1994b).

A agricultura biológica foi desenvolvida pelo político suíço Hans Peter Müller, pelo médico alemão Hans Peter Rush que, na década de 1960, aprimorou e disseminou as propostas de Müller e pelo francês Claude Aubert que as difundiu nos anos 1970. Consoante com (Ehlers, 1994a), as propostas desta agricultura são: adubação orgânica e mineral do solo; rotação de culturas; manejo adequado do solo de maneira a manter o crescimento e a manutenção de sua microbiota.

A agricultura natural respeita as "leis da natureza", realizando uma mínima intervenção no ambiente e processos naturais (Fukuoka, 1995). Este tipo de agricultura, idealizada por Mokiti Okada, sustenta as seguintes práticas agrícolas: rotação de culturas, utilização de adubos verdes, emprego de composto e uso de cobertura mortas - restos vegetais -sobre o solo mantendo o controle de pragas e doenças de acordo com as características da natureza. Op. Cit. (1994a).

Já o termo "alternativo" engloba todas as propostas descritas anteriormente, qualificando todas as formas de agricultura que adotam técnicas contrárias àquelas consideradas convencionais.

Para Almeida (1998), a agroecologia busca constituir-se em um campo de conhecimento científico, com forte dimensão social. Tem como pressuposto básico a diversidade ambiental, sociocultural e dos sistemas agrícolas, enfatizando a importância do resgate da agricultura convencional e do desenvolvimento adaptado à realidade local.

$\mathrm{Na}$ visão de Ehlers (1994b), a "agricultura sustentável" é considerada um objetivo a ser alcançado, uma forma de pensar ou uma filosofia. Não é uma prática agrícola ou um método, o que normalmente é mais fácil definir. Diferentes técnicas 
podem ser adotadas ao se objetivar a agricultura sustentável, desde que atendidas algumas exigências:

\begin{abstract}
...surgiram centenas de definições para explicar o que se entende por agricultura sustentável. Quase todas procuram expressar a necessidade do estabelecimento de um novo padrão produtivo que não agrida o ambiente e que mantenha as características dos agroecossistemas por longos períodos. E o mais provável é que esse novo padrão combine práticas convencionais e alternativas. No entanto, a noção de agricultura sustentável permanece cercada de imprecisões e de contradições, permitindo abrigar desde aqueles que se contentam com simples ajustes no atual padrão produtivo, até aqueles que vêem nessa noção um objetivo de longo prazo que possibilite mudanças estruturais, não apenas na produção agrícola mas em toda a sociedade (EHLERS, 1994b, p. 117).
\end{abstract}

Este entendimento de agricultura sustentável se alinha com a visão alternativa de sustentabilidade, "entrando para o conjunto das grandes utopias modernas, como a justiça social, a liberdade ou a democracia e só pode ser entendida como um objetivo, certamente a longuíssimo prazo" (EHLERS, 1994b, p.139).

\title{
O MUNICÍPIO DE RIO DAS OSTRAS (RJ) - UM EXEMPLO DE AGRICULTURA SUSTENTÁVEL
}

Como exemplo de aplicação prática da agricultura sustentável, pode ser citado o caso do município de Rio das Ostras, pertencente à região das Baixadas Litorâneas, no estado do Rio de Janeiro. Na localidade de Cantagalo, zona rural do município, foi implantado um programa de incentivo ao plantio de feijão praticado pela agricultura familiar. De acordo com chefe geral da Empresa Brasileira de Pesquisa Agropecuária (Embrapa), Pedro Arraes, "O incentivo do município de Rio das Ostras à produção familiar é um exemplo para o Brasil” (SECOM, 2009).

Ainda de acordo com Arraes, Rio das Ostras oferece ao produtor as seguintes condições: apoio técnico e toda uma variedade de feijões adaptadas, proporcionando uma produção limpa, evitando que o produtor utilize defensivos químicos. Constitui-se assim, em um 'subsídio do bem'.

De acordo com o Secretário de Meio Ambiente, Agricultura e Pesca, Max José de Almeida, "o reconhecimento e respaldo da Embrapa ao nosso programa de 
incentivo ao plantio confirma que estamos no caminho certo da agricultura sustentável, com respeito ao meio ambiente" (SECOM, 2009).

Este projeto de incentivo faz parte do Programa de Renda no Campo, da Secretaria de Meio Ambiente, Agricultura e Pesca e, principalmente, uma parceria da prefeitura de Rio das Ostras com os agricultores, na qual a administração municipal concede todo o apoio técnico e insumos e os produtores revertem parte do que foi investido em feijão.

É importante acrescentar que tal iniciativa começou no ano de 2005, alcançando uma produtividade de 680 quilos por hectare. Já em 2006, essa marca elevou-se para 1074 quilos por hectare e, em 2007, atingiu 1,1 tonelada por hectare (Op. Cit. 2009).

\section{SEGURANÇA ALIMENTAR}

Entende-se por segurança alimentar a capacidade do ser humano em ter como certa a ingestão das três principais refeições, diariamente: café da manhã, almoço e jantar. Adotando a visão da Comissão Mundial sobre o Meio Ambiente e Desenvolvimento CMMAD (1991), a produção de alimentos terá que aumentar de 3 a 4\%, anualmente, nas próximas décadas, para poder dar conta do crescimento da demanda. Assim, combinar o oferecimento da segurança alimentar à população do mundo, que se encontra em acelerado ritmo de crescimento, com a necessidade da preservação dos recursos naturais, constituir-se-á, de acordo com alguns autores, notadamente Ehlers (1994a), em um dos grandes desafios do século XXI.

E, novamente utilizando os preceitos da (CMMAD, 1991), verifica-se que a segurança alimentar resulta no mais importante objetivo do desenvolvimento rural e agrícola sustentável e, destarte, exige uma melhoria substancial da produção de alimentos e que possam atender ao direito da população a uma alimentação adequada.

Para que a meta acima citada possa ser alcançada, o incremento na produção de alimentos poderá ser realizado de três formas: 
a) Expandindo-se a área cultivada pelo uso de terras ociosas, sendo que isto acarretará em mais problemas ambientais do que em benefícios alimentares;

b) Intensificando-se o cultivo nas atuais áreas agrícolas, o que demandará mais consumo de água, fertilizantes, energia fóssil e muita pesquisa. Poder-se-ia utilizar a engenharia genética para a maximização da produção, o que geraria plantas mais resistentes ao ataque das pragas, porém a engenharia genética ainda não possui participação de vulto na provisão alimentar mundial;

c) Segundo Goodland (1997) apud Lima (2000), consumindo-se mais alimentos vegetais em detrimento de carnes. A alimentação vegetariana diminuiria os custos sócio-ambientais em relação à dieta baseada na carne, além do que, aumentaria a produção de grãos para o consumo humano.

De acordo com a Comissão Interministerial para Preparação das Conferências das Nações Unidas sobre Meio Ambiente e Desenvolvimento - CIMA (1991), também podem ser citados os seguintes fatores fundamentais para a segurança alimentar, tais como: o aumento da produção global; a redução das discrepâncias estruturais do mercado mundial de alimentos; o deslocamento da produção de alimentos para áreas acometidas pelo flagelo da fome; a garantia, a todas as pessoas, especialmente as mais pobres, de acesso a alimentos, e a conservação e proteção da base de recursos para a produção de alimentos a longo prazo.

Podemos, a partir do exposto acima, depreender que a articulação entre o crescimento econômico e a segurança alimentar configura-se como um fator sine qua non para a sustentação do nível de desenvolvimento atual e, mais do que isto, para a superação do subdesenvolvimento e, "cabe aos governos formular, introduzir e monitorar políticas públicas para se atingir a segurança alimentar dentro do processo de desenvolvimento sustentável”. (LIMA, 2000, p. 226).

\section{CONSIDERAÇÕES FINAIS}

É um fato evidente que a agricultura convencional, fundamentada na Revolução Verde, acarreta problemas sócio-econômicos e ambientais, bem como os prognósticos para solucioná-los, mediante uma alteração do atual paradigma de 
produção agrícola, ainda exigirão algum tempo tanto em investimentos, quanto em pesquisa.

Para Ehlers (1994a), a agricultura alternativa surge como a forma sustentável de produção agrícola, em potencial no futuro da humanidade, visto que ela reduzirá os custos de produção, mantendo a rentabilidade dos sistemas convencionais, produzindo alimentos saudáveis com a utilização de práticas compatíveis com o equilíbrio do meio ambiente.

Nos países subdesenvolvidos, onde existem desigualdades sociais acintosas, juntamente com a quase inexistência do desenvolvimento de tecnologia própria, somados aos problemas ambientais gerados pelo uso inadequado da tecnologia, encontra-se talvez, o maior desafio para a sustentabilidade.

No Brasil, de acordo com Maluf (1995), torna-se necessária a mudança das prioridades da política agrícola, com a revisão das formas sociais de produção no campo, o programa de reforma agrária. E, para Lima (2000), entende-se que as políticas públicas devem incentivar as mudanças no processo de produção e restringir as práticas que agridam o meio ambiente.

Neste contexto, é importante novamente citar que a agricultura sustentável é possível de ser implantada, desde que conte com os incentivos e a vontade política de todos os atores envolvidos. Voltando ao exemplo do projeto de plantio de feijão praticado pela agricultura familiar em Rio das Ostras, pôde-se constatar que tal iniciativa vem obtendo taxas de produtividade por hectare crescentes desde de sua implantação, em 2005 (SECOM, 2009).

As transformações não devem ocorrer apenas quanto ao conjunto tecnológico adotado para esta ou aquela produção, mas, como afirma Ehlers (1994a), devem considerar ainda a democratização do uso da terra, o que facilitaria a erradicação da fome e da miséria no mundo. 


\section{REFERÊNCIAS BIBLIOGRÁFICAS}

ALMEIDA, Jalcione. Tecnologia "moderna" versus tecnologia "alternativa": a luta pelo monopólio de competência tecnológica na agricultura. Porto Alegre: UFRGS, 1989. 274f. Dissertação (Mestrado em Sociologia Rural) - Programa de Pós-Graduação em Sociologia Rural, Universidade Federal do Rio Grande do Sul, Porto Alegre, 1989.

. Significados sociais, desafios e potencialidades da agroecologia. In:

FERREIRA, A.D.D.; BRANDENBURG, A. Para pensar outra agricultura. Curitiba: UFPR, 1998. p.239-247.

COMISSÃO Interministerial para Preparação das Conferências das Nações Unidas sobre Meio Ambiente e Desenvolvimento - CIMA. O desafio do desenvolvimento sustentável. Brasília: CIMA, 1991. 204 p.

COMISSÃO Mundial sobre o Meio Ambiente e Desenvolvimento - CMMAD. Em busca do desenvolvimento sustentável. In: Nosso futuro comum. 2. Ed. Rio de Janeiro: Ed. Fundação Getúlio Vargas, 1991, p.46-71.

Segurança alimentar: mantendo o potencial. In: Nosso futuro comum. 2. Ed. Rio de Janeiro: Fundação Getúlio Vargas, 1991, p. 129-161.

COSTA, M. Princípios de agricultura alternativa. In: AGRICULTURA ALTERNATIVA - SEMINÁRIOS DE PESQUISA, 1984, Londrina. Anais... Londrina: [s.n.], 1984. p. 116.

Princípios da agricultura alternativa. In: SIMPÓSIO DE AGRICULTURA ECOLÓGICA, 1993, Campinas. Anais.... Campinas: Cargil, 1993. p.1-16.

COSTA NETO, C. Agricultura Sustentável, tecnologia e sociedades. In: Mundo Rural e Tempo Recente, p. 301-321, 1999.

EHLERS, E. A agricultura alternativa: uma visão histórica. Estudos Econômicos, São Paulo, v. 24, especial, p.231-262, 1994a. 
Agricultura Sustentável: origens e perspectivas de um novo paradigma. São Paulo: Livros da Terra, 1996. 178p.

O que se entende por agricultura sustentável? São Paulo: USP, 161f. Dissertação (Mestrado em Ciência Ambiental) - Programa de Pós-Graduação em Ciência Ambiental, Universidade de São Paulo, São Paulo, 1994b.

- Possíveis veredas da transição à agricultura sustentável. Agricultura Sustentável, Jaguariúna, vol. 2, n. 2, p. 12-22, jul./dez. 1995.

FUKUOKA, M. Agricultura Natural. São Paulo: Nobel, 1995. 300p.

LIMA, E. F. Agricultura Sustentável: Origem e Perspectivas. Sociedade e Natureza, vol. 12, n. 23, p.213-229, jan./jun. 2000.

MALUF, R. S. Segurança alimentar, desenvolvimento sustentável e planejamento agro-alimentar. Agricultura Sustentável, Jaguariúna, v. 2, n. 2, p.34-44, jul./dez. 1995.

SECRETARIA de Comunicação de Rio das Ostras - SECOM. Rio das Ostras é exemplo de agricultura sustentável. Disponível na Internet: http://www.riodasostras.net/content/view/2378/85/, em 18. mai. 2010.

VEIGA, J. E. O Desenvolvimento Agrícola: Uma Visão Histórica. São Paulo: EDUSP/HUCITEC, 1991. 219 p.

VIEITES, R. G. Agricultura Sustentável: uma alternativa ao modelo convencional. In: XVIII ENCONTRO NACIONAL DE GEOGRAFIA AGRÁRIA. 2006 Anais... Rio de Janeiro: Uerj, [s/d]. CD-ROM.

(Recebido em dezembro/2009. Aceito em junho/2010) 